\title{
Therapeutic approach to FSGS in children
}

\author{
Debbie S. Gipson - Keisha Gibson • Patrick E. Gipson • \\ Sandra Watkins • Marva Moxey-Mims
}

Received: 25 May 2006 / Revised: 21 July 2006 / Accepted: 27 July 2006 / Published online: 16 November 2006

(C) IPNA 2006

\begin{abstract}
Therapy of primary focal segmental glomerulosclerosis (FSGS) in children incorporates conservative management and immunosuppression regimens to control proteinuria and preserve kidney function. In long-term cohort studies in adults and children with primary FSGS, renal survival has been directly associated with degree of proteinuria control. This educational article reviews the current therapeutic approach toward children with primary FSGS.
\end{abstract}

\section{Keywords ESRD $\cdot$ Proteinuria $\cdot$ Children $\cdot$ FSGS}

\section{Introduction}

Focal segmental glomerulosclerosis (FSGS) is a histologic finding that may result from a variety of insults to the kidney. FSGS typically presents with proteinuria and has a high risk of progressive loss of renal function [1]. Treatment of secondary forms of FSGS targets control of the underlying condition. Therapy of primary FSGS incorporates conservative management and immunosup-

D. S. Gipson $(\bowtie) \cdot$ K. Gibson • P. E. Gipson

Chapel Hill School of Medicine, University of North Carolina

Kidney Center, University of North Carolina,

7012 Burnett-Womack Hall, CB\#7155, Chapel Hill,

NC 27599-7155, USA

e-mail: Debbie_Gipson@med.unc.edu

S. Watkins

Children's Hospital and Regional Medical Center,

Seattle, WA, USA

\section{Moxey-Mims}

National Institutes of Health/National Institute of Diabetes and Digestive and Kidney Diseases,

Bethesda, MD, USA pression regimens to control proteinuria and preserve kidney function. In long-term cohort studies in adults and children with primary FSGS, renal survival has been directly associated with degree of proteinuria control (Fig. 1) [2,3]. Patients who are resistant to therapies have a significant likelihood of progressing to end-stage renal disease (ESRD) and are a group in need of novel therapies to delay or prevent this outcome [4].

\section{Genetic considerations}

An undefined proportion of patients with classically defined primary FSGS harbor genetic mutations in podocytespecific genes such as nephrin, podocin, $\alpha$-actinin- 4 , and CD2AP $[5,6]$. There are conflicting reports about the effectiveness of immune-based therapy in the setting of these mutations, but the likelihood of a positive response may be low [7]. Although mutation-linked cases of FSGS may have a lower response rate to conventional immunomodulatory treatment, these patients still manifest the progressive fibrosis that is observed in nongenetic FSGS.

\section{Nonimmunosuppressive therapy}

Diuretic therapy

Control of edema in nephrotic syndrome allows not only cosmetic improvement but is expected to decrease pulmonary effusions, decrease ascites, and lower the risk of peritonitis and skin-related problems from edema. Overaggressive diuresis in patients with intravascular depletion may be a risk factor, however, in developing thrombotic complications and acute renal insufficiency. 
Fig. 1 a Kaplan-Meyer analysis of the risk of end-stage renal disease (ESRD) by proteinuria remission status in children with primary focal segmental glomerulosclerosis (FSGS). b Kidney survival by proteinuria remission status in adults with primary FSGS. $C R$ complete remission, $P R$ partial remission, $N R$ no remission
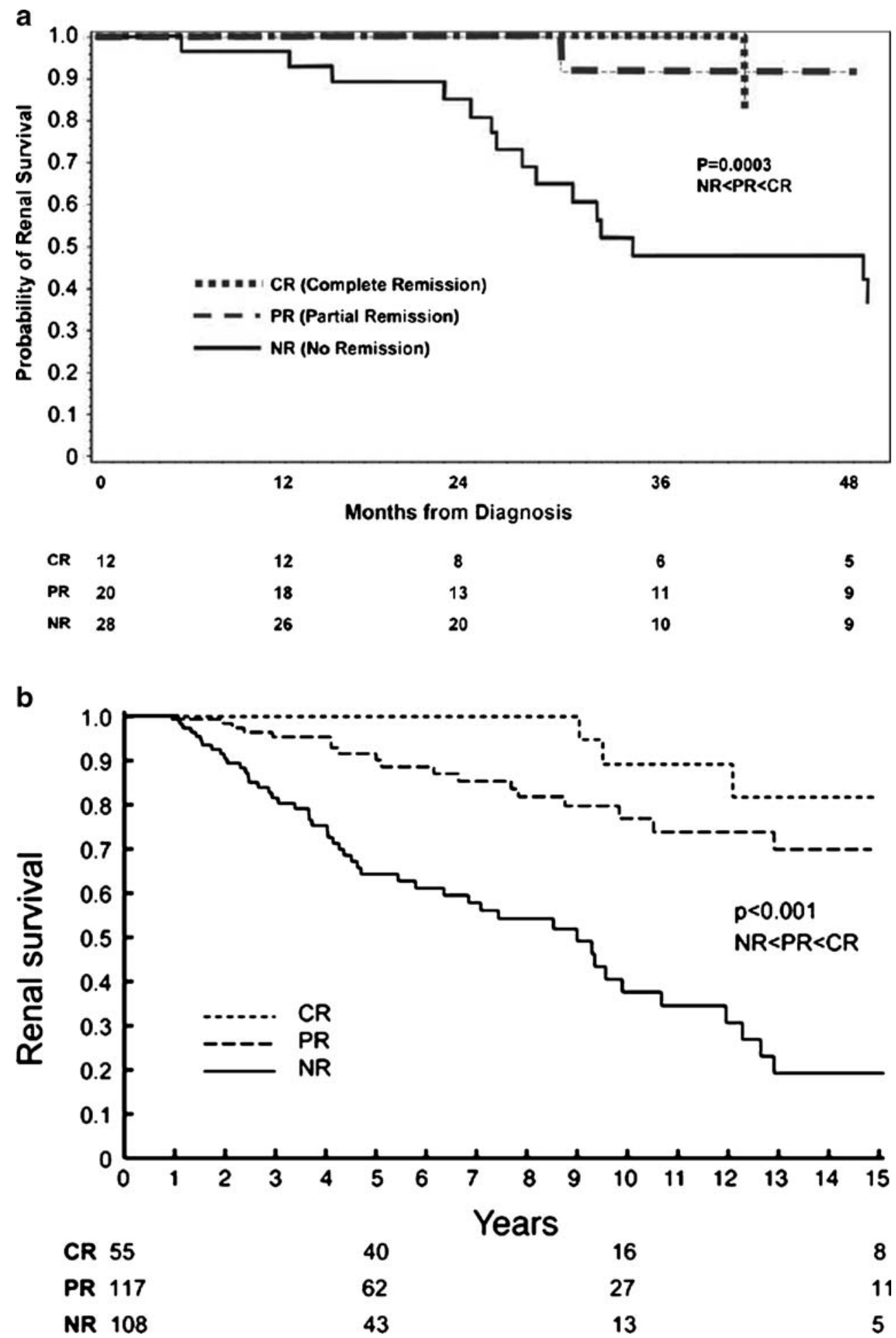

Loop diuretics are often required for control of edema in patients with proteinuria in the nephrotic range. Delivery of the diuretic to the site of action (lumen of the tubule) is often impaired in nephrotic syndrome due to decreased glomerular filtration rate (GFR), increased binding of the diuretic to intraluminal albumin, and/or decreased delivery of sodium to sites of diuretic activity. An increase of sodium reabsorption in the distal tubule in response to loop diuretic activity may add to resistance to loop diuretics. This distal compensatory mechanism may be diminished by the use of a combination of loop and distal diuretics (thiazides) [8]. Though the addition of aldosterone inhibitors (spironolactone) is theoretically attractive under the theory that edema is in part driven by aldosterone, it is 
unclear whether spironolactone or other similar medications are clinically helpful to control edema [9-11] An additional advantage to the use of aldosterone inhibitors such as spironolactone is suggested by the antifibrotic properties of these agents, which will be discussed below [12].

Combined albumin and furosemide therapy for anasarca has been studied, as well. Na et al. showed evidence for a mild increase in water diuresis but little evidence that the concomitant use of albumin adds to the natruretic effect of furosemide [13, 14]. Fliser et al. [15] showed a moderate $(20 \%)$ increase in water and salt excretion when comparing albumin and furosemide to furosemide alone. Haws et al. [16] also showed a mild but transient benefit of albumin and furosemide therapy but commented on the potential serious complications of hypertension, respiratory distress, congestive heart failure, and electrolyte disturbances. Thus, the combination of albumin and furosemide infusions, whether in combination or sequential, may provide a small transient benefit in the therapy of children with severe edema [17].

Treatment of hyperlipidemia

For patients who become nephrotic from the progression of FSGS, hyperlipidemia is an almost universal finding. Whether the hyperlipidemia associated with nephrotic syndrome should be specifically targeted for treatment in children separately from nephrotic syndrome treatment itself has been a question for more than 20 years. The childhood origin of atherosclerotic disease and increased risk for cardiovascular disease secondary to chronic kidney disease supports an interventional approach.

The report of the expert panel on blood cholesterol levels in children and adolescents [18] from the National Cholesterol Education Program (NCEP) defined categories of hypercholesterolemia in children for total cholesterol and low-density lipoprotein (LDL) cholesterol levels. High levels for total cholesterol were defined as $\geq 200 \mathrm{mg} / \mathrm{dl}$ and for LDL cholesterol as $\geq 130 \mathrm{mg} / \mathrm{dl}$. Dietary treatment of hyperlipidemia is the first-line intervention. In adults with nephrotic syndrome, soy-based vegetarian diets and supplemented low protein diets have been shown to have potential benefits, decreasing both proteinuria and cholesterol, but have not been shown to slow the decline in GFR $[19,20]$. Dietary therapy for dyslipidemia has been effective in reducing lipid levels in children with primary lipid disorders [21].

Based on the report from the NCEP, pharmacologic therapy for children ages 10 years and older should be considered after an adequate trial of diet therapy if LDL cholesterol remains $\geq 160 \mathrm{mg} / \mathrm{dl}$ in children with significant risk for cardiovascular disease, as is seen in children with FSGS. Recommendations for pharmacologic therapy for hyperlipidemia in children from the report suggested that bile acid sequestrants cholestyramine and colestipol should be the first-line agents for treating children with lipid disorders [18]. This was due mainly to concerns about the safety of 3-hydroxy-3-methylglutaryl coenzyme A (HMG $\mathrm{CoA}$ ) reductase inhibitors (statins) in children. While they are effective in lowering cholesterol and are relatively safe, bile acid sequestrants pose particular problems in children. They are not very palatable, and they may affect absorption of other medications being used, including thiazide diuretics, propranolol, corticosteroids, thyroid hormones, and loop diuretics. A new medication in this category, colesevelam, apparently does not have these problems but is not approved for use in children.

Since the NCEP report in 1992, several studies have been published suggesting that statins are safe in children as young as 4 years of age with familial hypercholesterolemia and do not adversely affect growth, hormone levels, or sexual development [21-23]. Statins are effective in treating the hypercholesterolemia of nephrotic syndrome, with decreases in total cholesterol levels up to $45 \%$ [24]. The long-term benefit of statins on renal function may be positive. Down stream from glomerular injury, high levels of urinary protein pass to the renal tubule and are reabsorbed. Protein reabsorption may injure the renal tubule. Statins may inhibit this tubular protein reabsorption and thereby protect from additional renal injury. Whether statins provide renoprotective effects in children has not been well studied, but there are several studies in adults with nondiabetic proteinuria that indicate that statins may slow GFR decline [25]. In these studies, the greatest benefit seemed to accrue in patients with the greatest amount of proteinuria and renal insufficiency. The side effects of statins have mainly been limited to myopathy and hepatotoxicity $[26,27]$.

Drugs in the fibrate class have also been used alone and in combination to treat hypercholesterolemia in children with nephrotic syndrome [28]. The use of gemfibrozil with a statin may increase the incidence of myopathy. Fenofibrate, approved for adult use in January 2006, may have less interaction due different hepatic metabolism [29]. The long-term safety of fibrates in children has not been well established.

\section{Alteration of the renin-angiotensin-aldosterone axis}

Blood pressure control for children with FSGS targets values less than or equal to the 90th percentile for age, gender, and height and is consistent with recommendations for all children with kidney disease. Evidence from many trials using angiotensin-converting enzyme inhibitor (ACE-I) and/or angiotensin receptor blocker (ARB) therapy in patients with proteinuria indicate that, beyond their anti- 
hypertensive effect, both are effective in reducing proteinuria in a wide variety of renal diseases. Few studies have had significant numbers of patients with FSGS specifically, and fewer still have included children with FSGS. In 1988, Trachtman and Gauthier reported a $50-70 \%$ reduction in proteinuria in children with steroid-resistant nephrotic syndrome (SRNS) using ACE-I therapy [30]. Bagga et al. [31], in a randomized, crossover trial of low-dose $(0.2 \mathrm{mg} / \mathrm{kg})$ vs. high-dose $(0.6 \mathrm{mg} / \mathrm{kg})$ enalapril in 25 patients with SRNS showed dose related responses, with average urine albumin/creatinine ratio reductions of $33 \%$ and $52 \%$, respectively. Blood pressure control was similar between the two groups. Several other studies of enalapril and ramipril in children with a variety of proteinuric renal diseases have confirmed the efficacy of these drugs in reducing proteinuria in many, but not all, treated children [32-35]. In the Ramipril Efficacy in Nephropathy (REIN) study, a double-blind study in adults with nondiabetic nephropathy, treatment with ramipril seemed to reduce both proteinuria and the rate of GFR decline more than could be attributed to blood pressure control alone [36]. Wühl et al., in a similar trial in almost 400 children with hypoplasia/dysplasia (70\%) and glomerulopathies (13\%), had similar findings [37].

There have been many studies in adults with renal disease comparing combined ACE-I/angiotensin receptor blocker (ARB) therapy with monotherapy alone [38, 39]. Though differing in design and findings, overall, the studies seem to indicate greater reduction in proteinuria without a greater frequency of side effects [39-41]. Yang et al. [41] reported greater reduction in proteinuria with combined therapy in a small group of five children with immunoglobulin (Ig)A nephropathy and heavy proteinuria, with no significant side effects noted. The most concerning side effect of ACE-I and ARB therapy is in females of childbearing years, with significant risk of fetal abnormalities reported with in utero exposure [42]. Other side effects of ACE-I therapy were noted in $2.4 \%$ of children in one large series with ramipril in children with chronic renal failure [37]. These side effects included decreases in GFR and hemoglobin and increases in serum potassium levels. Acute renal failure, often associated with hypovolemia, has been noted and seems to respond to discontinuation of the medicine until the acute illness resolves. Angioedema and nonproductive cough have been encountered with the use of ACE-I therapy in adults and are less frequently reported in children. ARBs seem to have a lower incidence of angioedema and cough [43, 44]. The incidence of recurrent angioedema in those who experience ACE-I-associated angioedema and are switched to ARB therapy appears to be low [45].

Aldosterone inhibitors have shown potential for alteration of the fibrotic mechanisms in animal models of kidney fibrosis, in the reduction of proteinuria in diabetic nephropathy, and in proteinuric chronic kidney diseases $[12,46,47]$. In the later study of 40 patients with a variety of proteinuric kidney diseases, the combination of ACE-I and aldosterone inhibitor therapy led to a decrease in mean urinary protein excretion in the ten patients assigned to this study arm [48]. Studies in humans with FSGS have not been published.

\section{Antioxidants}

The potential for antioxidant therapy in FSGS stems from experimental data that supports a role for excessive free radicals in multiple disease states, including chronic kidney disease. Based on antioxidant properties, vitamin $\mathrm{E}$ has been evaluated as a potential therapy for FSGS in one small study by Tahzib et al. In this open-label study, 11 children with FSGS were treated with vitamin $\mathrm{E}$ for approximately 3 months. A reduction in protein excretion was noted [49]. The antioxidant properties of vitamin $\mathrm{E}$ and the relatively low risk for adverse effects of this agent make this an interesting, if unproven, therapeutic option. The combined conservative management approach may control morbidity but leave the majority of patients with uncontrolled urinary protein excretion and risk for progression of disease. The typical approach to FSGS therapy in children is to add immunosuppression at the onset of therapy.

\section{Immunosuppression}

\section{Corticosteroids}

Corticosteroids have long been the mainstay of treatment for childhood nephrotic syndrome, regardless of its etiology. The huge role that these agents play is evident in the way this disease is classified: steroid responsive, steroid dependent, and steroid resistant. The International Study of Kidney Disease in Children (ISKDC) standard dosing has been, and generally continues to be, applied. That is, an 8-week course of oral prednisone at $60 \mathrm{mg} / \mathrm{m}^{2} /$ day for 4 weeks, followed by $40 \mathrm{mg} / \mathrm{m}^{2}$ on alternate days for 4 weeks [50]. Initial ISKDC data showed a corticosteroid response rate of approximately $30 \%$ of the 37 children with FSGS studied, and subsequent studies have been consistent in showing a response to oral corticosteroids in a minority of FSGS patients [51]. However, a response to corticosteroids is generally consistent with a more favorable prognosis, even when an initial response is followed by resistance after a subsequent relapse. There are also reported population differences in the response to steroid treatment, such as decreased response in African Americans and Hispanics [52]. Some literature is emerging that shows a lower response rate for patients with the nephrosis 2 homolog, podocin (human) (NPHS2) muta- 
tion [53]. The more recent debate has been about what steroid, how much steroid, and for how long, before a patient can be definitely declared unresponsive. Certainly, data in adult patients advocate prolonged oral corticosteroid administration, in some cases $>6$ months [54]. There have been no pediatric trials of prolonged oral corticosteroid use in patients with FSGS. The regimens used vary tremendously, with the most dramatic differences occurring between pediatric nephrologists and internist nephrologists. Due to the generally poor response to the standard oral dosing, some pediatric protocols have advocated high doses of intravenous methylprednisolone, with varying degrees of success [54, 55]. Corticosteroids remain a key component of many therapeutic regimens for FSGS, usually in combination with the various other drugs used to treat this disease, such as alkylating agents or calcineurin inhibitors. Of course, corticosteroid therapy is not without side effects. These include hypertension, growth impairment with prolonged therapy, susceptibility to infection, diabetes mellitus, and osteoporosis [55]. These side effects have led to the tendency toward lower corticosteroid doses and shorter, rather than prolonged, courses.

Calcineurin inhibitors

\section{Cyclosporine A}

The rationale behind the initial use of cyclosporine A (CsA) in FSGS and other forms of nephrotic syndrome is the evidence in animal models that the disease may be mediated by lymphokines that mediate glomerular basement membrane damage although it is unclear that this is actually the case. CsA acts on T-helper cells to inhibit interleukin-2 (IL-2) production, cytotoxic T-cell proliferation, and activation of B-cell responses by helper T-cells. However, CsA likely induces remission in proteinuria by two other mechanisms: induction of vasoconstriction of the glomerular afferent arteriole and interference with glomerular basement membrane permselectivity to proteins [56].

It has been two decades since CsA was first reported to show some benefit for patients with idiopathic nephrotic syndrome, especially for patients with steroid-responsive disease who had frequent relapses. One randomized trial of 49 steroid-resistant patients assigned to either CsA or placebo for 6 months showed a benefit in the CsA arm, with a response rate of $70 \%$ (complete or partial remission). This is the only medication with documented efficacy for steroid-resistant FSGS in controlled clinical trials in both adults and children [57, 58]. A major concern of long-term CsA treatment is the well-documented potential for nephrotoxicity. Another is the high relapse rate after drug withdrawal. In the Cattran study [57], $60 \%$ of the patients who responded to treatment had relapsed by week 78 .
There is also now concern being raised about secondary resistance developing in patients treated with CsA: an initial induction of remission, relapse when the drug is withdrawn, and resistance on reinstitution of the drug [59]. In this study of 32 children, the diagnosis of FSGS and the presence of $\mathrm{C} 4$ or $\mathrm{C} 1 \mathrm{q}$ during immunofluorescence staining of kidney tissue appear to correlate with an increased risk of secondary resistance. There are still no guidelines for standardized dosing or duration of treatment of children with steroid-resistant nephrotic syndrome, which probably accounts for the variability in reported response to treatment in the literature.

Side effects of CsA treatment include hypertension, hirsutism, and gingival hyperplasia. As a result of these and the risk for nephrotoxicity, treatment with cyclosporine has not been without controversy in terms of perceived optimal daily dosing, blood level to be maintained, and duration of treatment. A recent Egyptian study in 117 children with nephrotic syndrome, which included 79 patients with FSGS, used low-dose, long-term CsA (more than 2 years of treatment) [60]. The starting dose of $4-5 \mathrm{mg} / \mathrm{kg}$ per day was adjusted to maintain a whole-blood trough level of $100-150 \mathrm{ng} / \mathrm{ml}$ during the first 2 months and $50-100 \mathrm{ng} / \mathrm{ml}$ thereafter. In these subjects with steroid-resistant FSGS, the investigators were able to achieve an almost $70 \%$ complete remission rate during the 6 months of therapy. Unfortunately, the relapse rate was substantial upon withdrawal of CsA. Overall, it appears that, as with corticosteroids, a positive response to CsA, even if followed by a relapse, is a good prognostic indicator with regard to the risk for progression to ESRD [57].

\section{Tacrolimus}

This newer and more potent calcineurin inhibitor has not undergone a controlled clinical trial for the treatment of FSGS, but there are anecdotal reports of responses in patients with nephrotic syndrome, some of whom had FSGS [61]. One retrospective study of 16 children with treatment-resistant nephrotic syndrome, including 13 with FSGS, documented reduction in urinary protein excretion in 13 while on therapy and subsequent relapse in three of the 13 [62]. There are also two small prospective studies in adults that showed a positive response [63, 64]. In these small studies, tacrolimus appeared to present a problem similar to that of CsA, with a majority of patients relapsing on drug withdrawal [63].

\section{Alkylating agents}

DNA alkylating agents such as cyclophosphamide and chlorambucil have been in use since the 1980s for several glomerular diseases, including FSGS. The use of these 
agents has been limited due to potential side effects, including bone marrow suppression, infertility, hemorrhagic cystitis, and possible future malignancy risk. A retrospective cohort of 29 patients suggested that cyclophosphamide may have some survival benefit in those with at least a partial response measured by impact on proteinuria and progression of chronic kidney disease [65]. A randomized trial in 1996 from the ISKDC evaluated 60 children with FSGS and their response to daily oral cyclophosphamide and alternate day prednisone vs. alternate day prednisone alone. There was no difference in renal survival or proteinuria between the two groups [66]. Due to unfavorable toxic side effects and variable reported efficacy in the literature, alkylating agents are falling out of favor for primary therapy in FSGS.

\section{Mycophenolate mofetil}

Mycophenolate mofetil (MMF) was introduced in the mid-1990s as an immunosuppressive agent for organ transplantation. Due to its steroid-sparing effect, efforts have been made to expand its clinical application to several glomerular diseases, including FSGS. MMF blocks de novo synthesis of T- and B-cell lymphocytes through noncompetitive, reversible inhibition of inosine monophosphate dehydrogenase. Data on the use of MMF in FSGS has been limited to a few uncontrolled trials with small numbers of patients, but it shows early promise. Choi et al. reported 46 patients with primary glomerulopathies, including 18 patients with FSGS. They found a statistically significant decrease in proteinuria in patients receiving $\mathrm{MMF}$ as adjunctive therapy [67]. Cattran et al. reported an openlabel, 6-month trial of MMF in 18 patients with steroidresistant FSGS, 12 of whom were also resistant to alkylating agents and/or calcineurin inhibitors. Although patients did not achieve complete remission, four of $18 \mathrm{had}$ a reduction in proteinuria during therapy [68]. A similar decrease in proteinuria was documented in a series of nine children and young adults with steroid-resistant FSGS who were treated with pulse steroids and MMF [69]. Overall, MMF is showing early promise as a steroid-sparing therapy in FSGS, but questions remain about length of therapy, escalation of dosing, and long-term malignancy risks.

\section{Sirolimus}

The utility of sirolimus in the treatment of FSGS has been entertained in patients with intolerance or resistance to corticosteroid therapy. One prospective nonrandomized study documented a reduction of proteinuria in 12 of 21 patients treated with 6 months of sirolimus [70]. Conversely, a study of six FSGS patients treated with sirolimus documented a decline in kidney function in five patients.
None had a complete remission [71]. In transplant recipients, the use of sirolimus in conjunction with calcineurin inhibitors has also been associated with acute renal failure [72]. Consequently, sirolimus is not recommended for the treatment of FSGS due to the associated renal toxicity.

\section{Plasmapheresis}

In multiple-drug-resistant primary FSGS, the use of plasmapheresis has been considered a rescue option. The generally accepted rationale is for the removal of a circulating factor from the plasma that alters glomerular barrier function [73]. In primary FSGS in the native kidneys, two small studies encompassing 19 patients reported a response rate between $12 \%$ and $55 \%[74,75]$. The best response was seen using a protocol of plasmapheresis, corticosteroids, and cyclophosphamide, making it difficult to attribute the full response to plasmapheresis alone [75]. A single case report of a child with resistant disease demonstrated improved proteinuria and serum creatinine [76]. At present, plasmapheresis is considered a rescue therapy and is an invasive procedure with significant risks of infection, hypocalcemia, and bleeding. Plasmapheresis is considered an option for prevention or treatment of recurrent FSGS in the transplant recipient based on uncontrolled studies $[77,78]$.

\section{Antifibrotic therapy}

There are a large number of patients with multiple-drugresistant FSGS who are at substantial risk of progression to ESRD and for whom there are no proven therapeutic options. The past decade has witnessed striking advances in understanding the cellular and molecular basis of renal fibrosis and its contribution to progressive kidney failure. Several therapeutic targets have been identified in animal models of fibrosis in the kidney, including molecules involved in the recruitment and activation of mononuclear cells (e.g., chemokines, lymphokines, adhesion molecules), recruitment and activation of interstitial myofibroblasts, fibrogenic molecules [e.g., transforming growth factor (TGF)- $\beta$, endothelin-1, angiotensin II, tumor necrosis factor (TNF)- $\alpha$, and platelet-derived growth factor (PDGF)- $\beta$ ], angiogenic factors [e.g., vascular endothelial growth factor (VEGF)], antiapoptotic molecules, inhibitors of matrix synthesis, and molecules that enhance matrix degradation (matrix-degrading proteases, blockers of protease inhibitors) [79-83]. Crossing many of these mechanisms, peroxisome proliferator activator receptor- $\gamma$ $(\operatorname{PPAR} \gamma)$ agonists alter regulation of renal cell differentiation and proliferation [84-87], extracellular matrix production, macrophage accumulation, tissue inflammation, and apoptosis [88]. The most effective treatment to prevent progression of fibrosis and kidney failure in FSGS is likely 
to entail a combination of drugs that modulate mediators of fibrosis. The progression of kidney fibrosis is interrupted in part by the use of ACE-I and ARB agents in FSGS therapy. Future therapeutic options are likely to emanate from this area of research.

\section{Conclusions}

Current strategies for control of FSGS use a stepwise approach with a goal of normalization of urinary protein excretion and the prevention of kidney failure. Progress in this field remains a priority in order to prevent the trajectory toward renal failure for patients proven to be resistant to treatment and to identify therapeutic regimens with minimal toxicity.

\section{CME questions}

(Answers appear following the reference list)

1. A 14-year-old boy presents with nephrotic syndrome, normal serum creatinine, and normal blood pressure. $\mathrm{He}$ is diagnosed with FSGS by kidney biopsy and treated with corticosteroids. What is the most likely response to corticosteroids in this setting?
a. Complete remission with corticosteroid therapy
b. Dependence on corticosteroids
c. Failure to respond to corticosteroids but improves with cyclosporine
d. Failure to control proteinuria and progression to kidney failure

2. Factors that seem to confer an unfavorable prognosis in children with nephrotic syndrome are:
a. Primary resistance to corticosteroids
b. Resistance to cyclosporine
c. Presence of NPHS2 podocin mutation
d. African American or Hispanic ethnicity
e. All of the above

3. In the management of FSGS, progressive kidney fibrosis may be slowed by:
a. Furosemide
b. Angiotensin receptor blockade
c. Cholestyramine
d. Prednisone
e. Both $b$ and $d$

4. FSGS patients with NPHS2 podocin mutation are more likely to respond to corticosteroids than patients without a podocin mutation (T/F).

5. Cyclophosphamide is considered a mainstay in therapy for FSGS to prevent progression to end-stage renal failure $(\mathrm{T} / \mathrm{F})$.

\section{References}

1. Benchimol C (2003) Focal segmental glomerulosclerosis: pathogenesis and treatment. Curr Opin Pediatr 15:171-180

2. Troyanov S, Wall CA, Miller JA, Scholey JW, Cattran DC (2005) Focal and segmental glomerulosclerosis: definition and relevance of a partial remission. J Am Soc Nephrol 16:1061-1068

3. Gipson DS, Chin H, Presler TP, Jennette C, Ferris ME, Massengill S, Gibson K, Thomas DB (2006) Differential risk of remission and ESRD in childhood FSGS. Pediatr Nephrol 21:344-349

4. Cattran DC, Rao P (1998) Long-term outcome in children and adults with classic focal segmental glomerulosclerosis. Am J Kidney Dis 32:72-79

5. Caridi G, Bertelli R, Carrea A, Di Duca M, Catarsi P, Artero M, Carraro M, Zennaro C, Candiano G, Musante L, Seri M, Ginevri F, Perfumo F, Ghiggeri GM (2001) Prevalence, genetics, and clinical features of patients carrying podocin mutations in steroidresistant nonfamilial focal segmental glomerulosclerosis. J Am Soc Nephrol 12:2742-2746

6. Pollak MR (2003) The genetic basis of FSGS and steroid-resistant nephrosis. Semin Nephrol 23:141-146

7. Ruf RG, Lichtenberger A, Karle SM, Haas JP, Anacleto FE, Schultheiss M, Zalewski I, Imm A, Ruf EM, Mucha B, Bagga A, Neuhaus T, Fuchshuber A, Bakkaloglu A, Hildebrandt F (2004) Patients with mutations in NPHS2 (podocin) do not respond to standard steroid treatment of nephrotic syndrome. J Am Soc Nephrol 15:722-732

8. Wilcox CS (2002) New insights into diuretic use in patients with chronic renal disease. J Am Soc Nephrol 13:798-805

9. Usberti M, Gazzotti RM (1998) Hyporeninemic hypoaldosteronism in patients with nephrotic syndrome. Am J Nephrol 18:251-255

10. Usberti M, Gazzotti RM, Poiesi C, D’Avanzo L, Ghielmi S (1995) Consideration on the sodium retetention in nephrotic syndrome. Am J Nephrol 15:38-47

11. Shapiro MD, Hasbargen J, Hensen J, Schrier RW (1990) Role of aldosterone in the sodium retention of patients with nephrotic syndrome. Am J Nephrol 10:44-48

12. Aldigier JC, Kanjanbuch T, Ma LJ, Brown NJ, Fogo AB (2005) Regression of existing glomerulosclerosis by inhibition of aldosterone. J Am Soc Nephrol 16:3306-3314

13. Na KY, Han JS, Kim YS, Ahn C, Kim S, Lee JS, Bae KS, Jang IJ, Shin SG, Huh W, Jeon US (2001) Does albumin preinfusion potentiate diuretic action of furosemide in patients with nephrotic syndrome? J Korean Med Sci 16:448-454

14. Akcicek F, Yalniz T, Basci A, Ok E, Mees EJ (1995) Diuretic effect of frusemide in patients with nephrotic syndrome: is it potentiated by intravenous albumin? BMJ 310:162-163

15. Fliser D, Zurbruggen I, Mutschler E, Bischoff I, Nussberger J, Franek E, Ritz E (1999) Coadministration of albumin and furosemide in patients with the nephrotic syndrome. Kidney Int 55:629-634

16. Haws RM, Baum M (1993) Efficacy of albumin and diuretic therapy in children with nephrotic syndrome. Pediatrics 91:1142-1146

17. Elwell RJ, Spencer AP, Eisele G (2003) Combined furosemide and human albumin treatment for diuretic-resistant edema. Ann Pharmacother 37:695-700

18. American Academy of Pediatrics (1992) National cholesterol education program: report of the expert panel on blood cholesterol levels in children and adolescents. Pediatrics 89:525-584

19. D’Amico G, Remuzzi G, Maschio G, Gentile MG, Gotti E, Oldrizzi L, Manna G, Mecca G, Rugiu C, Fellin G (1991) Effect of dietary proteins and lipids in patients with membranous nephropathy and nephrotic syndrome. Clin Nephrol $35: 237-242$ 
20. Barsotti G, Morelli E, Cupisti A, Bertoncini P, Giovannetti S (1991) A special, supplemented 'vegan' diet for nephrotic patients. Am J Nephrol 11:380-385

21. Holmes KW, Kwiterovich PO Jr (2005) Treatment of dyslipidemia in children and adolescents. Curr Cardiol Rep 7:445-456

22. Clauss SB, Holmes KW, Hopkins P, Stein E, Cho M, Tate A, Johnson-Levonas AO, Kwiterovich PO (2005) Efficacy and safety of lovastatin therapy in adolescent girls with heterozygous familial hypercholesterolemia. Pediatrics 116:682-688

23. Wiegman A, Hutten BA, de GE, Rodenburg J, Bakker HD, Buller HR, Sijbrands EJ, Kastelein JJ (2004) Efficacy and safety of statin therapy in children with familial hypercholesterolemia: a randomized controlled trial. JAMA 292:331-337

24. Coleman JE, Watson AR (1996) Hyperlipidaemia, diet and simvastatin therapy in steroid-resistant nephrotic syndrome of childhood. Pediatr Nephrol 10:171-174

25. Agarwal R (2006) Effects of statins on renal function. Am J Cardiol 97:748-755

26. Mukhtar RY, Reckless JP (2005) Statin-induced myositis: a commonly encountered or rare side effect? Curr Opin Lipidol 16:640-647

27. de DS, Spinler SA, Miller K, Peterson AM (2004) Statins and liver toxicity: a meta-analysis. Pharmacotherapy 24:584-591

28. Buyukcelik M, Anarat A, Bayazit AK, Noyan A, Ozel A, Anarat R, Aydingulu H, Dikmen N (2002) The effects of gemfibrozil on hyperlipidemia in children with persistent nephrotic syndrome. Turk J Pediatr 44:40-44

29. Jones PH, Davidson MH (2005) Reporting rate of rhabdomyolysis with fenofibrate + statin versus gemfibrozil + any statin. Am J Cardiol 95:120-122

30. Trachtman H, Gauthier B (1988) Effect of angiotensin-converting enzyme inhibitor therapy on proteinuria in children with renal disease. J Pediatr 112:295-298

31. Bagga A, Mudigoudar BD, Hari P, Vasudev V (2004) Enalapril dosage in steroid-resistant nephrotic syndrome. Pediatr Nephrol 19:45-50

32. Milliner DS, Morgenstern BZ (1991) Angiotensin converting enzyme inhibitors for reduction of proteinuria in children with steroid-resistant nephrotic syndrome. Pediatr Nephrol 5:587-590

33. Proesmans W, Wambeke IV, Dyck MV (1996) Long-term therapy with enalapril in patients with nephrotic-range proteinuria. Pediatr Nephrol 10:587-589

34. Lama G, Luongo I, Piscitelli A, Salsano ME (2000) Enalapril: antiproteinuric effect in children with nephrotic syndrome. Clin Nephrol 53:432-436

35. Seeman T, Dusek J, Vondrak K, Flogelova H, Geier P, Janda J (2004) Ramipril in the treatment of hypertension and proteinuria in children with chronic kidney diseases. Am J Hypertens 17:415-420

36. (1997) Randomised placebo-controlled trial of effect of ramipril on decline in glomerular filtration rate and risk of terminal renal failure in proteinuric, non-diabetic nephropathy. The GISEN Group (Gruppo Italiano di Studi Epidemiologici in Nefrologia). Lancet 349:1857-1863

37. Wühl E, Mehls O, Schaefer F (2004) Antihypertensive and antiproteinuric efficacy of ramipril in children with chronic renal failure. Kidney Int 66:768-776

38. Kincaid-Smith P, Fairley K, Packham D (2002) Randomized controlled crossover study of the effect on proteinuria and blood pressure of adding an angiotensin II receptor antagonist to an angiotensin converting enzyme inhibitor in normotensive patients with chronic renal disease and proteinuria. Nephrol Dial Transplant 17:597-601

39. Nakao N, Yoshimura A, Morita H, Takada M, Kayano T, Ideura T (2003) Combination treatment of angiotensin-II receptor blocker and angiotensin-converting-enzyme inhibitor in non-diabetic renal disease (COOPERATE): a randomised controlled trial. Lancet 361:117-124
40. Ruilope LM, Aldigier JC, Ponticelli C, Oddou-Stock P, Botteri F, Mann JF (2000) Safety of the combination of valsartan and benazepril in patients with chronic renal disease. European Group for the Investigation of Valsartan in Chronic Renal Disease. J Hypertens 18:89-95

41. Yang Y, Ohta K, Shimizu M, Nakai A, Kasahara Y, Yachie A, Koizumi S (2005) Treatment with low-dose angiotensin-converting enzyme inhibitor (ACEI) plus angiotensin II receptor blocker (ARB) in pediatric patients with IgA nephropathy. Clin Nephrol 64:35-40

42. Quan A (2006) Fetopathy associated with exposure to angiotensin converting enzyme inhibitors and angiotensin receptor antagonists. Early Hum Dev 82:23-28

43. Lo KS (2002) Angioedema associated with candesartan. Pharmacotherapy 22:1176-1179

44. Irons BK, Kumar A (2003) Valsartan-induced angioedema. Ann Pharmacother 37:1024-1027

45. Cicardi M, Zingale LC, Bergamaschini L, Agostoni A (2004) Angioedema associated with angiotensin-converting enzyme inhibitor use: outcome after switching to a different treatment. Arch Intern Med 164:910-913

46. Sato A, Hayashi K, Naruse M, Saruta T (2003) Effectiveness of aldosterone blockade in patients with diabetic nephropathy. Hypertension 41:64-68

47. Rachmani R, Slavachevsky I, Amit M, Levi Z, Kedar Y, Berla M, Ravid M (2004) The effect of spironolactone, cliazapril, and their combination on albuminuria in patients with hypertension and diabetic nephropathy is independent of blood pressure reduction: A randomized controlled study. Diabet Med 21:471-475

48. Chrysostomou A, Pedagogos E, MacGregor L, Becker GJ (2006) Double-blind, placebo controlled study on the effect of the aldosterone receptor antagonist spironolactone in patients with have persistent proteinuria and are on long-term angiotensinconverting enzyme inhibitor therapy, with or without an angiotensin II receptor blocker. Clin J Am Soc Nephrol 1:256-262

49. Tahzib M, Frand R, Gauthier B, Valderrama E, Trachtman H (1999) Vitamin E treatment of focal segmental glomerulosclerosis: results of an open-label study. Pediatr Nephrol 13:649-652

50. (1978) Nephrotic syndrome in children: prediction of histopathology from clinical and laboratory characteristics at time of diagnosis. A report of the international study of kidney disease in children. Kidney Int 13:159-165

51. (1985) Focal segmental glomerulosclerosis in children with idiopathic nephrotic syndrome. A report of the Southwest Pediatric Nephrology Study Group. Kidney Int 27:442-449

52. Ingulli E, Tejani A (1991) Racial differences in the incidence and renal outcome of idiopathic focal segmental glomerulosclerosis in children. Pediatr Nephrol 5:393-397

53. Karle SM, Uetz B, Ronner V, Glaeser L, Hildebrandt F, Fuchshuber A (2002) Novel mutations in NPHS2 detected in both familial and sporadic steroid-resistant nephrotic syndrome. J Am Soc Nephrol 13:388-393

54. Mendoza SA, Tune BM (1992) Treatment of childhood nephrotic syndrome. J Am Soc Nephrol 3:889-894

55. Kirpekar R, Yorgin PD, Tune BM, Kim MK, Sibley RK (2002) Clinicopathologic correlates predict the outcome in children with steroid-resistant idiopathic nephrotic syndrome treated with pulse methylprednisolone therapy. Am J Kidney Dis 39:1143-1152

56. Zietse R, Wenting GJ, Kramer P, Schalekamp MA, Weimar W (1992) Effects of cyclosporin A on glomerular barrier function in the nephrotic syndrome. Clin Sci (Lond) 82:641-650

57. Cattran DC, Appel GB, Hebert LA, Hunsicker LG, Pohl MA, Hoy WE, Maxwell DR, Kunis CL (1999) A randomized trial of cyclosporine in patients with steroid-resistant focal segmental glomerulosclerosis. North America Nephrotic Syndrome Study Group. Kidney Int 56:2220-2226 
58. Lieberman KV, Tejani A (1996) A randomized double-blind placebo-controlled trial of cyclosporine in steroid-resistant idiopathic focal segmental glomerulosclerosis in children. J Am Soc Nephrol 7:56-63

59. Sairam VK, Kalia A, Rajaraman S, Travis LB (2002) Secondary resistance to cyclosporin $\mathrm{A}$ in children with nephrotic syndrome. Pediatr Nephrol 17:842-846

60. El-Husseini A, El-Basuony F, Mahmoud I, Sheashaa H, Sabry A, Hassan R, Taha N, Hassan N, Sayed-Ahmad N, Sobh M (2005) Long-term effects of cyclosporine in children with idiopathic nephrotic syndrome: a single-centre experience. Nephrol Dial Transplant 20:2433-2438

61. McCauley J, Shapiro R, Ellis D, Igdal H, Tzakis A, Starzl T (1993) Pilot trial of FK506 in the management of steroid-resistant nephrotic syndrome. Nephrol Dial Transplant 8:1286-1290

62. Loeffler K, Gowrishankar M, Yiu V (2004) Tacrolimus therapy in pediatric patients with treatment-resistant nephrotic syndrome. Pediatr Nephrol 19:281-287

63. Segarra A, Vila J, Pou L, Majo J, Arbos A, Quiles T, Piera LL (2002) Combined therapy of tacrolimus and corticosteroids in cyclosporin-resistant or -dependent idiopathic focal glomerulosclerosis: a preliminary uncontrolled study with prospective follow-up. Nephrol Dial Transplant 17:655-662

64. Duncan N, Dhaygude A, Owen J, Cairns TD, Griffith M, McLean AG, Palmer A, Taube D (2004) Treatment of focal and segmental glomerulosclerosis in adults with tacrolimus monotherapy. Nephrol Dial Transplant 19:3062-3067

65. Geary DF, Farine M, Thorner P, Baumal R (1984) Response to cyclophosphamide in steroid-resistant focal segmental glomerulosclerosis: a reappraisal. Clin Nephrol 22:109-113

66. Tarshish P, Tobin JN, Bernstein J, Edelmann CM (1996) Cyclophosphamide does not benefit patients with focal segmental glomerulosclerosis. A report of the International Study of Kidney Disease in Children. Pediatr Nephrol 10:590-593

67. Choi MJ, Eustace JA, Gimenez LF, Atta MG, Scheel PJ, Sothinathan R, Briggs WA (2002) Mycophenolate mofetil treatment for primary glomerular diseases. Kidney Int 61:1098-1114

68. Cattran DC, Wang MM, Appel G, Matalon A, Briggs W (2004) Mycophenolate mofetil in the treatment of focal segmental glomerulosclerosis. Clin Nephrol 62:405-411

69. Montane B, Abitbol C, Chandar J, Strauss J, Zilleruelo G (2003) Novel therapy of focal glomerulosclerosis with mycophenolate and angiotensin blockade. Pediatr Nephrol 18:772-777

70. Tumlin JA, Miller D, Near M, Selvaraj S, Hennigar R, Guasch A (2006) A prospective, open-label trial of sirolimus in the treatment of focal segmental glomerulosclerosis. Clin J Am Soc Nephrol $1: 109-116$

71. Fervenza FC, Fitzpatrick PM, Mertz J, Erickson SB, Liggett S, Popham S, Wochos DN, Synhavsky A, Hippler S, Larson TS, Bagniewski SM, Velosa JA (2004) Acute rapamycin nephrotoxicity in native kidneys of patients with chronic glomerulopathies. Nephrol Dial Transplant 19:1288-1292

72. Lawsin L, Light JA (2003) Severe acute renal failure after exposure to sirolimus-tacrolimus in two living donor kidney recipients. Transplantation 75:157-160

73. Sharma M, Sharma R, McCarthy ET, Savin VJ (1999) "The FSGS factor:" enrichment and in vivo effect of activity from focal segmental glomerulosclerosis plasma. J Am Soc Nephrol 10:552-561

74. Feld SM, Figueroa P, Savin V, Nast CC, Sharma R, Sharma M, Hirschberg R, Adler SG (1998) Plasmapheresis in the treatment of steroid-resistant focal segmental glomerulosclerosis in native kidneys. Am J Kidney Dis 32:230-237

75. Mitwalli AH (1998) Adding plasmapheresis to corticosteroids and alkylating agents: does it benefit patients with focal segmental glomerulosclerosis? Nephrol Dial Transplant 13:1524-1528

76. Vecsei AK, Muller T, Schratzberger EC, Kircher K, Regele H, Arbeiter K, Schroth B, Aufricht C (2001) Plasmapheresis-induced remission in otherwise therapy-resistant FSGS. Pediatr Nephrol 16:898-900

77. Gohh RY, Yango AF, Morrissey PE, Monaco AP, Gautam A, Sharma M, McCarthy ET, Savin VJ (2005) Preemptive plasmapheresis and recurrence of FSGS in high-risk renal transplant recipients. Am J Transplant 5:2907-2912

78. Hubsch H, Montane B, Abitbol C, Chandar J, Shariatmadar S, Ciancio G, Burke G, Miller J, Strauss J, Zilleruelo G (2005) Recurrent focal glomerulosclerosis in pediatric renal allografts: the Miami experience. Pediatr Nephrol 20:210-216

79. Magil AB, Pichler RH, Johnson RJ (1997) Osteopontin in chronic puromycin aminonucleoside nephrosis. J Am Soc Nephrol 8:1383-1390

80. Wang Y, Wang YP, Tay YC, Harris DC (2001) Role of CD8(+) cells in the progression of murine adriamycin nephropathy. Kidney Int 59:941-949

81. Kojima K, Matsui K, Nagase M (2000) Protection of alpha(3) integrin-mediated podocyte shape by superoxide dismutase in the puromycin aminonucleoside nephrosis rat. Am J Kidney Dis $35: 1175-1185$

82. Nakamura S, Nakamura I, Ma L, Vaughan DE, Fogo AB (2000) Plasminogen activator inhibitor-1 expression is regulated by the angiotensin type 1 receptor in vivo. Kidney Int 58:251-259

83. Fan L, Wakayama T, Yokoyama S, Amano O, Iseki S (2002) Downregulation of vascular endothelial growth factor and its receptors in the kidney in rats with puromycin aminonucleoside nephrosis. Nephron 90:95-102

84. Guan YF, Breyer MD (2001) Peroxisome proliferator-activated receptors (PPARs): Novel therapeutic targets in renal disease. Kidney Int 60:14-30

85. Hsueh WA, Nicholas SB (2002) Peroxisome proliferator-activated receptor- $\gamma$ in the renal mesangium. Curr Opin Nephrol Hypertens 11:191-195

86. Nicholas SB, Kawano Y, Wakino S, Collins AR, Hsueh WA (2001) Expression and function of peroxisome proliferator-activated receptor-gamma in mesangial cells. Hypertension 37:722-727

87. Asano T, Wakisaka M, Yoshinari M, Iino K, Sonoki K, Iwase M, Fujishima M (2000) Peroxisome proliferator-activated receptor gammal (PPARgamma1) expresses in rat mesangial cells and PPARgamma agonists modulate its differentiation. Biochim Biophys Acta 1497:148-154

88. Yang HC, Ma LJ, Fogo AB (2006) Peroxisome proliferatoractivated receptor-gamma agonist is protective in podocyte injury-associated sclerosis. Kidney Int 69:1756-1764

\section{CME answers}
1. C
2. E
3. E
4. False
5. False 